\title{
INTUBATION STUDIES OF THE HUMAN SMALL INTESTINE. XXII. AN IMPROVED TECHNIC FOR THE STUDY OF ABSORPTION; ITS APPLICATION TO ASCORBIC ACID
}

\author{
By JOSEPH T. L. NICHOLSON AND FRANCIS W. CHORNOCK 1 \\ (From the Gastro-Intestinal Section (Kinsey-Thomas Foundation) of the Medical Clinic, \\ Hospital of the University of Pennsylvania, Philadelphia)
}

(Received for publication April 13, 1942)

\section{INTRODUCTION}

Recent advances in the study of human nutrition indicate that a clinical deficiency of vitamins or other food factors may occur not only because of an inadequate intake or because of faults in storage or in utilization within the body, but also because of faulty absorption from the digestive tract. Consequently an accurate, direct and quantitative method of estimating the absorption of such substances in the human, under controlled conditions, is urgently needed. Various technics, including some developed in this clinic since 1934, have been used as a basis for the method which we will now describe and which seems to have certain advantages over those previously employed. At the same time, to illustrate the practical value of the method, we will present certain observations on its application to the absorption of ascorbic acid from the duodenojejunal region of normal subjects. The results have been of such a nature as to suggest that the method is trustworthy and applicable to the testing of other substances in health and in disease.

\section{PREVIOUS METHODS}

The tests of absorption utilized in the past have been inadequate for several reasons. In the procedures dependent on the concentration of the substance in the blood, such as Althausen's (1) galactose method, the rate of withdrawal of the test material from the blood for utilization, storage, and excretion cannot be controlled. Balance studies of total intake against total output in the feces fail to yield exact data on absorption because of the uncertain influence of bacterial action on the test substance in the bowel and of the possibility of its absorption and subsequent excretion into that organ. The employment of intestinal intubation, as originally suggested by Miller and Abbott (2), gives more direct data on absorption, though such specific technics as have been described ( 3 to 6$)$ do. not permit the intestine to function

1 Sponsored by the Smith, Kline and French Laboratories, Inc. normally or eliminate the possibility of certain quantitative errors. The closed-loop intubation method $(3,4)$ prevents the admixture of gastric, intestinal, hepatic, and pancreatic secretions from above, which presumably is necessary for normal absorption. The open-loop technic of Groen (5), because of the amount of the substance introduced at one time, distorts the ratio of volume to area, thereby interfering with the normal absorptive mechanism. In these methods, also, the damming back of large volumes of the test solution above the distal delimiting balloon often leads to an escape of some of the material beyond the test area, particularly in the presence of abnormal peristalsis associated with a diseased state.

\section{CRITERIA OF A SATISFACTORY METHOD}

To determine the absorptive power of the intestine for a given substance, a solution of the latter should be brought into contact with the absorbing surface under conditions that duplicate insofar as possible those that occur during the normal digestion of food: the motor and secretory functions of the intestine should not be disturbed and the concentration of the substance in solution should be within the range of normal for that section of the bowel. In order to insure such a physiological state of the intestine, care should be taken to avoid any mechanical obstruction, such as a balloon above the area under study, which might interfere with the normal progress of peristalsis or a free flow downstream of the secretions from the stomach, liver and pancreas. At the same time a method of obturation of the distal end of the intestinal segment should be chosen that will confine the test solution to the area under study and yet not initiate any unusual intestinal reaction. The chemical and physical characteristics of the material to be introduced, its volume and its rate of flow should be within the range of normal for the human as determined by such studies as those of Karr and Abbott (7).

A satisfactory absorption technic should not only operate within these physiological limitations, but also should be a quantitative procedure. This requires the maximal application of the test substance to a known area of absorbing surface. Since the concentration of the test solution falls at a rate proportional to the rapidity of absorption, such maximal application demands that a shorter loop be used for studying the more rapidly absorbed substances. The absorptive period, furthermore, should have a sharp starting-point, and also some means should be provided for terminating the procedure abruptly 
at a fixed time and for withdrawing at that time all of the substance remaining within the test area.

\section{TECH NIC AND CHEMICAL METHODS}

The principle involved is the maintenance of a continuous perfusion from above downward of a physiologically acceptable solution through the lumen of a selected segment of small intestine, the functions of which are not disturbed by the procedure itself. Any portion of the bowel may be tested, but in our experiments the solution was introduced through one lumen of a double-lumened tube into the mid-duodenum (Figure $1, \mathrm{~A}^{\prime}$ ). Its rate of flow was $10 \mathrm{cc}$. per minute, which conforms to observations made in this clinic on the rate of gastric emptying. A concentration was chosen that would not produce intestinal irritation and yet would approach the normal absorptive capacity. From a point either 45 or $90 \mathrm{~cm}$. downstream (Figure 1, B') the gut contents were withdrawn

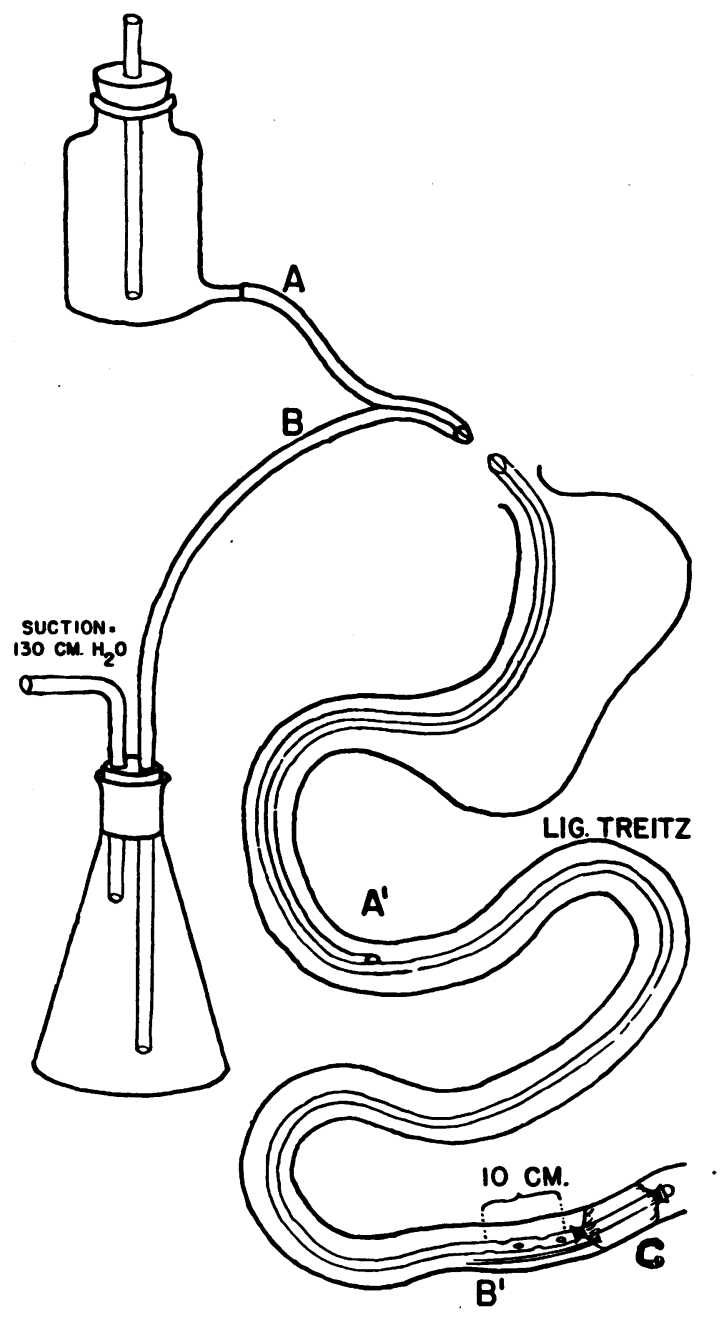

Fig. 1. Diagram to Illustrate the Technic EMPLOYED through a suitable prolongation of the other lumen of the double-lumened tube by continuous suction as fast as they accumulated. Since the withdrawal capacity of the apparatus was $175 \mathrm{cc}$. per minute, greatly in excess of the possible rate of accumulation, a balloon at the distal end of the tube (Figure 1, C) assisted in diverting the flow but did not constitute an obstruction in the sense of producing a pooling of intestinal contents.

The apparatus consists of a $90 \mathrm{~cm}$. double-lumened rubber tube, size $16 \mathrm{~F}$, which has suitable fittings at the upper end for connecting the larger lumen B to a collecting flask and the smaller lumen $A$ to a graduated Mariotte bottle. The lower end of the larger lumen is attached to either a 55 or a $100 \mathrm{~cm}$. single lumen duodenal tube, size $12 \mathrm{~F}$, which has multiple suction holes in the distal $10 \mathrm{~cm}$. A rubber balloon $\mathrm{C}$ is tied to the end of the single tube but does not communicate with its lumen. The inflation of this balloon is controlled by a separate $1.5 \mathrm{~mm}$. rubber tube which lies beside the larger tubing but communicates only with the balloon $\mathrm{C}$. The intubation is performed in such fashion as to bring the distal end of the double lumened tube within the transverse portion of the duodenum. Thus a solution flowing through lumen $A$ enters the mid-duodenum at $A^{\prime}$ while suction applied to lumen B constantly empties the intestine of its contents as fast as they arrive, either 45 or $90 \mathrm{~cm}$. lower down at $\mathbf{B}^{\prime}$.

An experiment began with a flow of the solution into the duodenum $\left(\mathrm{A}^{\prime}\right)$ and the simultaneous withdrawal of whatever material was present at the distal end of the test area $\left(B^{\prime}\right)$. An interval of several minutes intervened before the return flow began. The experiment was abruptly terminated at the end of one hour by a cessation of the perfusion and the immediate introduction of $30 \mathrm{cc}$. of a 30 per cent solution of magnesium sulfate into the upper end of the test area $\left(A^{\prime}\right)$. This cathartic served to wash down all the contents and itself appeared in the collecting bottle in from 1 to 4 minutes, as indicated by the presence of carbon particles that had been injected with it. Tap water at a rate of $10 \mathrm{cc}$. per minute for one-half hour was then instilled at $A^{\prime}$, immediately following the magnesium sulfate injection, and the resulting flow of fluid aspirated at $B^{\prime}$ was collected in 10-minute fractions. The results obtained by the use of the $90 \mathrm{~cm}$. technic in measuring absorption from a 10 per cent glucose solution over a period of 90 minutes are given as a working illustration in Table I. The presence of only a trace of glucose in the second 10-minute wash after the magnesium sulfate injection reveals the completeness with which the unabsorbed material may be removed.

For the determination of ascorbic acid in the blood, oxalated specimens were mixed, centrifuged, and samples withdrawn for analysis within a half hour after collection. The amount in the plasma was determined by the titration procedure of Farmer and $\operatorname{Abt}(8,9)$ and by the photometric method of Mindlin and Butler (10). For the ascorbic acid content of the urine and intestinal specimens, samples were collected in flasks containing $10 \mathrm{cc}$. of glacial acetic acid and then refrigerated until the 
TABLE I

The efficiency of the method as applied to the absorption of a 10 per cent solution of glucose from a $90 \mathrm{~cm}$. segment of duodenum and jejunum

\begin{tabular}{|c|c|c|c|c|}
\hline \multirow{2}{*}{ Time } & \multicolumn{2}{|l|}{ Instilled at $\mathbf{A}^{\prime}$} & \multicolumn{2}{|c|}{ Withdrawn at $\mathbf{B}^{\prime}$} \\
\hline & Volume & Glucose & Volume & Glucose \\
\hline $\begin{array}{r}\text { minutes } \\
0-30 \\
30-60 \\
60-90 \\
90-93 \\
\\
93-103 \\
103-113 \\
113-123 \\
125-127\end{array}$ & \begin{tabular}{|c|}
$c c$. \\
300 \\
300 \\
300 \\
30 \\
(30 per cent $\left.\mathrm{MgSO}_{4}\right)$ \\
100 \\
100 \\
100 \\
during removal of tu
\end{tabular} & $\left\{\begin{array}{c}\text { grams } \\
30 \\
30 \\
30 \\
0 \\
0 \\
0\end{array}\right.$ & $\begin{array}{l}c c . \\
265 \\
310 \\
320 \\
\\
225 \\
60 \\
87 \\
38\end{array}$ & $\begin{array}{r}\text { grams } \\
13.8 \\
16.7 \\
19.8 \\
7.0 \\
\\
\text { trace } \\
0.0 \\
\text { trace }\end{array}$ \\
\hline
\end{tabular}

Total gms. glucose injected 90.00

Total gms. glucose recovered $\mathbf{5 7 . 3 5}$

Total gms. glucose absorbed 32.65

* Represents results of continuous aspiration while withdrawing tube after completion of experiment.

experiment was completed. Then the volume was measured and suitable aliquots were removed either for the titration procedure or for dilution with 5 per cent acetic acid for the photometric method.

\section{RESULTS WITH ASCORBIC ACID}

The absorption of ascorbic acid in one hour from a $600 \mathrm{cc}$. solution containing $600 \mathrm{mgm}$. of this vitamin was determined by this technic in 19 experiments on 4 normal human adult subjects. To evaluate the effect of the previous ingestion of ascorbic acid on its absorption, experiments were performed on fasting individuals previously "saturated" by the daily intake, in addition to a regular diet, of $500 \mathrm{mgm}$. of ascorbic acid for one week as well as on "unsaturated" individuals. In 13 experiments, the absorption was measured for a segment extending $90 \mathrm{~cm}$. beyond the instillation point in the duodenum. In the remaining experiments, the test segment extended only $45 \mathrm{~cm}$. beyond the point of instillation. Because a water solution of ascorbic acid in this concentration may be sufficiently hypotonic to be irritating, as shown in dogs by Dennis (11), physiological saline was in some instances used as a solvent.

In Table II are given the results of 5 groups of experiments performed under the various conditions just stated. The amount of ascorbic acid absorbed by "saturated" and "unsaturated" subjects was approximately the same when either a
TABLE II

The absorption of ascorbic acid from the duodenum and upper jejunum in the normal human adult as determined by the described technic

\begin{tabular}{|c|c|c|c|c|c|c|}
\hline \multirow{2}{*}{$\begin{array}{l}\text { Sub- } \\
\text { ject }\end{array}$} & \multirow{2}{*}{$\begin{array}{l}\text { Status of } \\
\text { ascorbic acid } \\
\text { nutrition }\end{array}$} & \multirow{2}{*}{$\begin{array}{l}\text { Ascorbic } \\
\text { acid in } \\
\text { fasting } \\
\text { blood } \\
\text { plasma }\end{array}$} & \multirow{2}{*}{$\begin{array}{l}\text { Length } \\
\text { of per- } \\
\text { fused } \\
\text { segment }\end{array}$} & \multirow{2}{*}{$\begin{array}{l}\text { Nature of } \\
\text { solution }\end{array}$} & \multicolumn{2}{|c|}{$\begin{array}{c}\text { Ascorbic acid } \\
\text { absorbed in } \\
1 \text { hour }\end{array}$} \\
\hline & & & & & Total & $\begin{array}{l}\text { Per } \\
\text { 8q. } \mathrm{m} \text {. }\end{array}$ \\
\hline & & $\begin{array}{l}\text { mgm. } \\
\text { per cent }\end{array}$ & $\mathrm{cm}$. & $\begin{array}{l}600 \mathrm{mgm} . \\
\text { in } 600 \mathrm{cc} .\end{array}$ & mgm. & mgm. \\
\hline $\begin{array}{l}\mathrm{Br} \\
\mathrm{Hn} \\
\mathrm{Hn} \\
\mathrm{Cs}\end{array}$ & $\begin{array}{l}\text { unsaturated } \\
\text { unsaturated } \\
\text { unsaturated } \\
\text { unsaturated }\end{array}$ & 0.9 & $\begin{array}{l}90 \\
90 \\
90 \\
90\end{array}$ & $\begin{array}{l}\text { watery } \\
\text { watery } \\
\text { watery } \\
\text { watery }\end{array}$ & $\begin{array}{l}261 \\
369 \\
330 \\
374\end{array}$ & $\begin{array}{l}161 \\
187 \\
167 \\
174\end{array}$ \\
\hline $\begin{array}{l}\mathrm{Br} \\
\mathrm{Br} \\
\mathrm{Cs} \\
\mathrm{Cs}\end{array}$ & $\begin{array}{l}\text { saturated } \\
\text { saturated } \\
\text { saturated } \\
\text { saturated }\end{array}$ & $\begin{array}{l}1.7 \\
1.3 \\
2.0 \\
1.3\end{array}$ & $\begin{array}{l}90 \\
90 \\
90 \\
90\end{array}$ & $\begin{array}{l}\text { watery } \\
\text { watery } \\
\text { watery } \\
\text { watery }\end{array}$ & $\begin{array}{l}349 \\
325 \\
280 \\
252\end{array}$ & $\begin{array}{l}215 \\
201 \\
132 \\
119\end{array}$ \\
\hline $\begin{array}{l}\mathrm{Br} \\
\mathrm{Br} \\
\mathrm{Hn} \\
\mathrm{Cs} \\
\mathrm{Bt}\end{array}$ & $\begin{array}{l}\text { saturated } \\
\text { saturated } \\
\text { saturated } \\
\text { saturated } \\
\text { saturated }\end{array}$ & $\begin{array}{l}1.0 \\
1.3 \\
1.6 \\
1.6 \\
1.4\end{array}$ & $\begin{array}{l}90 \\
90 \\
90 \\
90 \\
90\end{array}$ & $\begin{array}{l}\text { saline } \\
\text { saline } \\
\text { saline } \\
\text { saline } \\
\text { saline }\end{array}$ & $\begin{array}{l}354 \\
232 \\
253 \\
253 \\
188\end{array}$ & $\begin{array}{l}219 \\
143 \\
128 \\
119 \\
132\end{array}$ \\
\hline $\begin{array}{l}\mathrm{Br} \\
\mathrm{Hn} \\
\mathrm{Bt}\end{array}$ & $\begin{array}{l}\text { unsaturated } \\
\text { unsaturated } \\
\text { unsaturated }\end{array}$ & $\begin{array}{l}0.4 \\
0.9 \\
0.7\end{array}$ & $\begin{array}{l}45 \\
45 \\
45\end{array}$ & $\begin{array}{l}\text { saline } \\
\text { saline } \\
\text { saline }\end{array}$ & $\begin{array}{l}292 \\
290 \\
197\end{array}$ & $\begin{array}{l}179 \\
147 \\
139\end{array}$ \\
\hline $\begin{array}{l}\mathrm{Br} \\
\mathrm{Hn} \\
\mathrm{Bt}\end{array}$ & $\begin{array}{l}\text { saturated } \\
\text { saturated } \\
\text { saturated }\end{array}$ & $\begin{array}{l}1.2 \\
1.1 \\
1.1\end{array}$ & $\begin{array}{l}45 \\
45 \\
45\end{array}$ & $\begin{array}{l}\text { saline } \\
\text { saline } \\
\text { saline }\end{array}$ & $\begin{array}{l}283 \\
308 \\
366\end{array}$ & $\begin{array}{l}175 \\
156 \\
258\end{array}$ \\
\hline
\end{tabular}

watery or a saline solution was used. Likewise the tonicity of the test solution did not alter the rate of absorption in the saturated individuals. Furthermore, the absorption of this vitamin from a segment terminated at $45 \mathrm{~cm}$. beyond the point of instillation was of the same degree as that in a segment terminated at $90 \mathrm{~cm}$. Although the absorption of ascorbic acid varied over a wide range, i.e., 188 to $374 \mathrm{mgm}$., or 31 to 62 per cent of the total injected, every subject absorbed an amount in one hour far in excess of the optimal daily intake of $100 \mathrm{mgm}$. as determined by Ralli et al. (12). When calculated on the basis of surface area, the amounts absorbed varied over an equally wide range.

\section{DISCUSSION}

Our experience with this method emphasizes its inherent advantages. Direct duodenal instillation avoids the variability of gastric emptying and allows the gut to fill and empty from above downward. Absorption, therefore, takes place without the participation of abnormal peristalsis, such as is 
initiated by the retrograde filling utilized in Groen's (5) experiments. Continuous aspiration above the point of obturation eliminates not only the possibility of leakage but also the effect of excessive distention on absorption. Furthermore, the immediate withdrawal of the test solution during the magnesium sulfate flushing terminates each experiment quickly and cleanly, in contradistinction to the inadequate and time consuming procedures utilized in the other technics. The pliability and small diameter of the tubing not only make intubation relatively easy but also allow the apparatus to pass into its proper position within 2 to 3 hours. The actual performance of the test does not cause the abdominal pain and retching which occur so frequently with the other methods. We believe, therefore, that this technic may be applied as a clinical procedure to any patient capable of tolerating a duodenal tube.

The efficiency of the procedure as a quantitative test is clearly illustrated by the experiment with glucose (Table I). Although the results with ascorbic acid have shown a varying rate of absorption in the same individual under similar conditions, this may have resulted from factors other than the reliability of the method. One suspects that, no matter how carefully the conditions of the experiment are controlled, the effectiveness of the gut as an absorptive organ actually changes from time to time. The observation that saturated individuals absorb the acid as well as unsaturated ones was not unexpected, since the raising of the plasma level from 0.4 to $1 \mathrm{mgm}$. per cent did not materially decrease the gradient between the concentration of the ascorbic acid in the test solution and that in the blood.

The absence of a significant difference between the amount of ascorbic acid absorbed from the 90 and from the $45 \mathrm{~cm}$. loops respectively illustrates the desirability of studying rapidly absorbed substances by a short loop. Maximal application of the test substance probably did not take place in the lower half of the $90 \mathrm{~cm}$. segment, because of the reduction in the concentration of the test solution brought about by rapid absorption in the upper half of the test area. It would seem, therefore, that, within the range of our experiments, the absorption of ascorbic acid was related more directly to the concentration of the test solution, than to the area of intestinal mucosa that was exposed to it.

From a clinical viewpoint, the significant observation is that the mucous membrane of the upper small intestine has a relatively enormous capacity for the absorption of ascorbic acid. If one calculates the absorbing power of the entire small gut for this vitamin from the figures we have obtained for a $45 \mathrm{~cm}$. segment over one hour, it is obvious that from 20 to 40 grams can be taken up within 24 hours. No exact data are available on the rapidity of flow that would be necessary to prevent the minimal required uptake of ascorbic acid from intestinal contents containing an average concentration of the substance, but it seems probable that a diarrhea to be capable of producing scurvy would have to be of great intensity.

\section{CONCLUSIONS}

By means of a modification of the intubation technic previously introduced for the study of human intestinal absorption, it has been possible to satisfy certain additional physiological and quantitative criteria. The application of the method to ascorbic acid indicates that the capacity of a short segment of the upper small intestine for the absorption of that vitamin within one hour is far in excess of the optimal daily requirement.

\section{BIBLIOGRAPHY}

1. Althausen, T. L., A test for intestinal absorption. Am. J. Digest. Dis., 1939, 6, 544.

2. Miller, T. G., and Abbott, W. O., Intestinal intubation: A practical technique. Am. J. M. Sc., 1934, 187, 595.

3. Abbott, W. O., and Miller, T. G., Intubation studies of the human small intestine. III. A technic for the collection of pure intestinal secretion and for the study of intestinal absorption. J. A. M. A., 1936, 106, 16.

4. Abbott, W. O., Karr, W. G., and Miller, T. G., Intubation studies of the human small intestine. VII. Factors concerned in absorption of glucose from the jejunum and ileum. Am. J. Digest. Dis. and Nutrition, 1938, 4, 742.

5. Groen, J., The absorption of hexoses from the upper part of the small intestine in man. J. Clin. Invest., 1937, 16, 245.

6. Shay, H., Gershon-Cohen, J., Fels, S. S., and Munro, F. L., The absorption and dilution of glucose 
solutions in the human stomach and duodenum. Am. J. Digest. Dis., 1939, 6, 535.

7. Karr, W. G., and Abbott, W. O., Intubation studies of the human small intestine. IV. Chemical characteristics of the intestinal contents in the fasting state and as influenced by the administration of acids, of alkalies and of water. J. Clin. Invest., $1935,14,893$.

8. Farmer, C. J., and Abt, A. F., Ascorbic acid content of the blood. Proc. Soc. Exper. Biol. and Med., $1935,32,1625$.

9. Farmer, C. J., and Abt, A. F., Determination of reduced ascorbic acid in small amounts of blood. Proc. Soc. Exper. Biol. and Med., 1936, 34, 146.

10. Mindlin, R. L., and Butler, A. M., The determination of ascorbic acid in plasma; a macromethod and a micromethod. J. Biol. Chem., 1938, 122, 673.

11. Dennis, C., Injury to ileal mucosa by contact with distilled water. Am. J. Physiol., 1940, 129, 171.

12. Ralli, E. P., Friedman, G. J., and Sherry, S., The vitamin $C$ requirement of man. Estimated after prolonged studies of the plasma concentration and daily excretion of vitamin $C$ in 3 adults on controlled diets. J. Clin. Invest., 1939, 18, 705. 